\title{
A Case Study of Intercultural Interventions for Chinese University Students During Study Abroad Program in the University of Minnesota
}

\author{
WANG Ju-lan (Colleen) \\ SHU-UTS Buisness School, Shanghai University, Shanghai, China
}

\begin{abstract}
In 21st Century, Chinese and American universities are experiencing great development in the number of students studying abroad. This research adopts the method of natural investigation, selecting Chinese student samples during study abroad program in the University of Minnesota to complete the designed questionnaires to examine the intercultural interventions taken before, during and after this type of study abroad in Chinese universities. Also, after students complete the questionnaires, email communication is made to analyze the reasons for their answers to the questionnaires. The questionnaire results and email communication show that there is a great gap in the practice of intercultural interventions in study abroad programs between Chinese universities and students expectations. It is time for Chinese universities to design appropriate intercultural interventions in order to maximize Chinese university students' intercultural development during study abroad. These intercultural interventions should be run consistently to cover the phrases of pre-departure, during and after the study abroad program. Also, more dynamic and interactive intercultural interventions rather than knowledge-based intercultural instructions or guidance should be the focus for intercultural interventions.
\end{abstract}

Keywords: intercultural interventions, study abroad program, intercultural competence, Chinese university students

\section{Introduction}

In 21st century, both China's government and America's government and universities as well have enacted many policies and taken various approaches to encourage and fund universities to study abroad. A number of studies have been conducted beyond Mainland China to assess the impact of study abroad on the development of cultural sensitivity, ethnorelative attitudes, or more generally, intercultural competence (Allen, Dristas, \& Mills, 2007; Tuleja, 2008; Leong, 2007; Engle, 2003; Jackson, 2009; Pedersen, 2010; Clarke III, Flaherty, Wright, \& McMillen, 2009). Overall, these studies demonstrate these programs can not automatically nurture the development of students' intercultural competence, but well-designed intercultural interventions can help students benefit from intercultural learning and thus develop their intercultural competence (Vande, Paige \& Lou, 2012, p. 29). In order to address this challenge, many American universities have designed effective

WANG Ju-lan (Colleen), Master Degree of Xiameng University, Ph.D. Candidate, Senior Lecturer at Shanghai University. 
intercultural programs to facilitate students' intercultural competence development while they are participating in study abroad programs (Harvey, 2013; Lou \& Bosley, 2008; Paige \& Goode, 2009).

In Mainland China, there is insufficient study in this field, and most study abroad programs, merely send students abroad, but do not provide comprehensive accompanying measures before, during and after the stay. "Inadequate preparation, unrealistic expectations, and unsettling intercultural encounters can have detrimental effects on short term sojourners perceptions, adjustment, and willingness to engage with host nationals" (Jackson, 2009, p. 60).

This study selects Chinese students participating in study abroad program in the University of Minnesota to complete the designed questionnaires to examine the intercultural interventions taken before, during and after this program in Chinese universities. Also, email communication is made to analyze the underlying reasons for their choices when they complete the questionnaires.

\section{Research Design}

\section{Research Questions}

The research questions particularly focus on the intercultural interventions taken by Chinese universities for Chinese students who are participating in study abroad program in the University of Minnesota and aim to answer the following questions: (1) What intercultural interventions are taken before students leave to take part in this program? (2) What intercultural interventions are taken while students are studying in this program in America? (3) What intercultural interventions are taken after students come back to China after this program? And (4) What intercultural interventions are expected by students participating in this program?

\section{Research Methods and Participants}

The study is a combination of quantitative and qualitative research by carrying out questionnaires among Chinese students and email communications with these students.

\section{Participants}

The questionnaire is designed by the author and is composed of four sections to address the research questions. It was sent out by Survey Monkey in October, 2016 to Chinese students participating the study abroad program with the help of one Chinese intern in Study Abroad Center of the University of Minnesota. Altogether 187 questionnaires were sent out and the number of valid questionnaires used in this study is 102 .

\section{Data Collection and Analysis}

\section{Background Information of the Participants}

Due to many different types of study abroad programs in the University of Minnesota, it is necessary to make a background analysis of these participants in the research.

Table 1 shows the background information of the participants in the questionnaire. 
Table 1

Background Information of the Participants

\begin{tabular}{|c|c|}
\hline Age & $20-22(n=78), 23-28(n=24)$ \\
\hline $\begin{array}{l}\text { Chinese universities } \\
\text { students come from }\end{array}$ & $\begin{array}{l}\text { Peking University }(\mathrm{n}=5) \text {, Tsinghua University }(\mathrm{n}=4) \text {, Beijing Agriculture University }(\mathrm{n}=3) \text { China } \\
\text { People University }(\mathrm{n}=6) \text {, China Politics and Law University }(\mathrm{n}=10) \text {, Nankai University }(\mathrm{n}=10) \text {, } \\
\text { Tianjin Physical Education and Sports University }(\mathrm{n}=3) \text {, Shanghai Jiaotong University }(\mathrm{n}=8) \text {, } \\
\text { Fudan University }(\mathrm{n}=4) \text {, Henbei Agriculture University }(\mathrm{n}=5) \text {, Qingdao University }(\mathrm{n}=18) \text {, Xian } \\
\text { Jiaotong University }(\mathrm{n}=3) \text {, Sichuan University }(\mathrm{n}=4) \text {, Chongqing University }(\mathrm{n}=4) \text {, Zhejiang } \\
\text { University }(\mathrm{n}=2) \text {, Sun Yat-Sen University }(\mathrm{n}=10) \text {, Nanchang University }(\mathrm{n}=3) \text {. }\end{array}$ \\
\hline Student category & Bachelor Degree students $(n=86)$, master degree students $(n=16)$ \\
\hline Study abroad program & $\begin{array}{l}\text { Exchange student program }(\mathrm{n}=11) \text {, visiting student for credits program }(\mathrm{n}=38) \text {, joint program }(\mathrm{n}= \\
\text { 3), transfer student program }(\mathrm{n}=50) \text {. }\end{array}$ \\
\hline Prog & One term $(n=24)$, one academic year $(n=28)$, more than one academic year $(n=50)$. \\
\hline
\end{tabular}

The background information reveals that all participants come from key universities in China. Specially, 28 students are from Beijing, 18 from Qingdao, and 12 from Shanghai. The higher level of internationalization of higher education in the top two cities (Beijing and Shanghai) in China may explain the larger percentage of the subjects in the study. The subsequent email communication reveals that there is a regular exchange student program of taking around 20 students run every year between Qingdao University and the University of Minnesota. Additionally, because of the long-term corporation between institute in China Politics and Law University, Nankai University, Sun Yat- Sen University and Law school and Carson Management School in the University of Minnesota, the number of students from these universities is also comparatively big. In terms of what kind of diploma students are pursuing, bachelor degree accounted for over $80 \%$, and the remaining students are studying for master degree. Almost half of the students choose to transfer to the university to continue their bachelor or master degree study after taking part in the study abroad program, which means they will not go back to their home universities in China.

\section{Pre-Departure Intercultural Interventions for Students Taking Part in the Study Abroad Program}

Intercultural interventions before departure are very important for smooth transition to a new cultural setting and is the first step for the success of intercultural learning because they can help students prepare for new cultural settings, either in a social or academic context (Jackson, 2009). There are various ways to develop students' readiness to transit to a new cultural setting. Table 2 shows the pre-departure intercultural interventions taken in Chinese universities and students' expectations of intercultural interventions.

Table 2

Pre-departure Intercultural Interventions

\begin{tabular}{|c|c|}
\hline Intercultural intervention type & Number \\
\hline \begin{tabular}{|l|} 
intercultural competence self-examination by taking \\
Intercultural Development Inventory (IDI)
\end{tabular} & $\mathrm{N}=0$ \\
\hline American Language and Culture Course study & $\mathrm{N}=26$ \\
\hline $\begin{array}{l}\text { Intercultural training programs carried out in } \\
\text { students' home universities }\end{array}$ & $\begin{array}{l}\text { Study abroad program self-study materials }(\mathrm{n}=102) \\
\text { Passport, visa, safety issues of study abroad training }(\mathrm{n}=102) \\
\text { Adapting to American academic culture training }(\mathrm{n}=0) \\
\text { Adapting to American social culture training }(\mathrm{n}=0) \\
\text { Intercultural communication training }(\mathrm{n}=0)\end{array}$ \\
\hline Intercultural interventions expected by students & $\begin{array}{l}\text { Taking Intercultural Development Inventory (IDI) }(\mathrm{n}=98) \\
\text { Academic features and requirements of American universities }(\mathrm{n}=68) \\
\text { Academic English writing training }(\mathrm{n}=94) \\
\text { Current American news, movies and other daily topics training }(\mathrm{n}=87)\end{array}$ \\
\hline
\end{tabular}


The statistics in Table 2 reveal that none of the students have taken the self-examination test of Intercultural Development Inventory (IDI). This tool is highly reliable and valid and used widely among international higher education and intercultural communication (Hammer, 2007, 2011). However, the participants in the study did not get the test of it from their mother schools in China. The reasons could be there is no qualified assessor of IDI in these universities, and intercultural learning is not included in their curriculum. The results show these universities in China assumethat study abroad programs can automatically develop students' intercultural competence without proper pre-departure intercultural training. A further examination of Study abroad program self-study materials mentioned by all participants shows that these materials generally provide knowledge-based information about target universities in America such as what courses they can chooseand what type of accommodation they can apply for. Safety issues of study abroad training basically cover information about how to stay safe and provide lists of can do and cannot do. In general, these materials tend to examine American safety from a negative perspective.

The lack of pre-departure intercultural interventions in the aspect of adapting to American academic and social culture obviously contrasts with students' expectation of receiving such training. Subsequent email responses from these students find that a majority of courses they take in the university require them to write academic essays. All essays are required to be written in an academic style and are submitted online to check plagiarism. Because of the lack of critical thinking training in many Chinese universities and the differences between Chinese essay writing and American essay writing, many participants undergo a difficult transition to academic culture in the university. Also, because of no training about American daily life culture, most participants mention that in the first few weeks, they encounter many difficulties like taking the bus and doing grocery shopping in their daily life. They also could not understand the jokes and some daily topics American teachers and their classmates talk about.

Overall, Table 2 reveals that Chinese universities generally provide pre-departure guidance by supplying students with knowledge-based materials and general instruction of applying for passport and visa and advice of staying safe in America. Since knowledge-based information can be easily accessed online, this guidance cannot actually prepare students to smoothly transit to a new academic and social culture which is not dynamic and interactive.

\section{During Study Abroad Program Intercultural Interventions}

After students are enrolled in the University of Minnesota, all participants receive various types of intercultural interventions from the university, but their home universities in China offer no relevant intercultural interventions. The results are represented in Table 3 below.

Table 3

During Study Abroad Program Intercultural Interventions

\begin{tabular}{|l|l|}
\hline $\begin{array}{l}\text { Intercultural interventions from } \\
\text { home universities in China }\end{array}$ & $\mathrm{N}=0$ \\
\hline & $\begin{array}{l}\text { Guidance for international newcomers }(\mathrm{n}=102) \\
\text { Academic success program for international students }(\mathrm{n}=16) \\
\text { Intercultural development programs for international students which include the following: } \\
\text { Intercultural study buddy program }(\mathrm{n}=39) \\
\text { Intercultural interventions from }\end{array}$ \\
$\begin{array}{l}\text { Intercultural ambassador ( }=25) \\
\text { Intercultural discussion groups }(\mathrm{n}=82) \\
\text { Intercultural coffee time ( }=49) \\
\text { Cultural group }(\mathrm{n}=24) \\
\text { Academic writing counselling }(\mathrm{n}=41)\end{array}$ \\
\hline
\end{tabular}


Table 3 shows that the University of Minnesota offers diversified support for international students to adapt to new cultural setting and prepares them to achieve success in academic study. These supporting programs are classified as compulsory and optional, free and fee-paying. All the international students must attend one-week free intercultural adaptation program guidance for international newcomers. As shown by table 3, all 102 participants in the study attended this compulsory course and the feedback from their emails suggests that they benefit a lot from the program because it covers the gap between their pre-departure intercultural interventions and their expectations. They mention that the program specifically show them the detailed requirements of their courses, offer them opportunities to learn from former international students, understand the challenges they are going to meet in their future study, etc. However, only 16 students paid to enroll in the academic success program for international students. The reason could be the fee is too high for the students and many of them expressed their worries. They doubt whether the one-week intensive academic success program can guarantee their success in the university and they also expressed their preference to learning how to achieve academic success while they are taking different courses. 39 students joined the buddy program with American students, 25 students attended intercultural activities organized by intercultural ambassador program, 82 students attended intercultural discussions at least once. These statistics show that these students really meet challenges in transiting to the new culture and they realized that they need some intercultural interventions to better develop their intercultural competence in their intercultural learning process.

\section{After Study Abroad Program Intercultural Interventions}

Intercultural learning is a long process. Finishing the study abroad program does not mean the end of intercultural learning. After study abroad program intercultural interventions offer great opportunities for students to reflect on what they have experienced when they are in a new culture. Appropriate after study abroad program intercultural interventions can deepen their intercultural learning and further develop their intercultural competence. Also, their experience and reflection can help the future students to study abroad. Table 4 below shows the currently running intercultural interventions in their home universities and their expectations.

Table 4

After Study Abroad Program Intercultural Interventions

\begin{tabular}{|l|l|}
\hline $\begin{array}{l}\text { After study abroad program intercultural interventions } \\
\text { currently run in your home universities }\end{array}$ & $\begin{array}{l}\text { Study abroad program overview }(\mathrm{n}=52) \\
\text { Your study abroad story }(\mathrm{n}=47) \\
\text { Study abroad photo and video showcase }(\mathrm{n}=18)\end{array}$ \\
\hline $\begin{array}{l}\text { After study abroad program intercultural intervention } \\
\text { you hope that home universities can run }\end{array}$ & $\begin{array}{l}\text { Study abroad communication week in the institute and in the } \\
\text { university (photo and video showcase, student-run seminars and } \\
\text { presentations) }(\mathrm{n}=52) \\
\text { Buddy program with international students }(\mathrm{n}=14) \\
\text { Reflective intercultural communication course }(\mathrm{n}=21) \\
\mathrm{IDI} \text { test }(\mathrm{n}=43)\end{array}$ \\
\hline
\end{tabular}

Table 4 shows there are only 52 participants answering the relevant questions because they are those who decide not to transfer to the University of Minnesota after the study abroad program. This means they will go back to their home universities. Those decide to transfer to this university did not answer these questions. This table shows that students are all encouraged to hand in their study abroad overview or report or story. However, 
many students think they can further carry on their intercultural learning in a deeper way by organizing more dynamic and interactive activities with the support from their home universities. For example, 52 students all expressed that a study abroad communication week can run in their universities so that they can have more opportunities to talk about and show what they have experienced when they are abroad. This can make them dig deeper into their intercultural learning by communicating with others in a more vivid way like organizing seminars and doing presentations. In a more interactive way, intercultural competence can be better developed. Also, 21 students hope that they can systematically learn an intercultural communication course to know more about the underlying theory for intercultural learning and thus strengthen their intercultural learning experience. 43 students want to take the IDI test to check to what degree that they have developed their intercultural competence after taking the study abroad program and to know the gap between them and a highly intercultural competent person. In this way, they can know what they can keep working on in their intercultural learning in the long run.

\section{Implications for Intercultural Interventions for Study Abroad Program in China's Universities}

The study shows that there is a lack of effective intercultural interventions before, during and after the study abroad program in China's university. This cannot support Chinese students in their intercultural learning journey and possibly make Chinese students encounter intercultural barriers, especially during the first one or two weeks when they arrive in America. Systematical intercultural interventions are suggested to be carried out. The program called "the first step conference" run in the University of Minnesota is a good example. This program requires all study abroad students to attend a three full day compulsory pre-departure training to learn about the online going intercultural learning guidance, online intercultural learning consultants, IDI (Intercultural Development Inventory) instructions, taking IDI to know their intercultural competence scale, join a buddy program to meet students from their host countries to talk about their host countries culture and make a plan for communicating with each other while they are in the host countries. During their study abroad time in the host countries, students are required to follow the course syllabus to study two online courses "Maximizing study abroad: A student's guide to strategies for language and culture learning and use and Global identity: international experience integrated into your future” (Paige, et.al. 2009). The online courses are supported by online intercultural learning consultants who provide appropriate guidance and advice to students according to their IDI scores. At the same time, students are required to hand in one reflective intercultural learning report every week to review and reflect on their intercultural learning and make plans for further intercultural learning in the following week. These two courses help student consistently and actively engaged in intercultural learning and their reflective report provides an ongoing evaluation of their intercultural competence development. Even though it is costly for the university to run the two courses for all study abroad students, this guide and support from home university really helped students foster their intercultural competence development in an active intercultural learning process (Paige \& Goode, 2009). For Chinese universities, they can learn from this example and develop their own courses based on Chinese students' features and need to guide them when they are in host universities. These courses should have clear intercultural learning objectives, authentic and interactive intercultural content, diversified intercultural 
activities and summative evaluation. Also, ongoing one-to-one online intercultural consulting is very crucial for the success of intercultural learning when students are studying abroad. It is not a wise action to just send students out and neglect their need for support in fitting into a new culture. When they are in the host countries, cultural immersion activities can really help students experience the local culture, but these immersion activities should be designed with the support of faculty or staff of the host universities. After they come back from the study abroad program, more opportunities and more diversified activities should be given to students to present and reflect their intercultural learning journey from different perspectives.

\section{Conclusion}

Intercultural learning is a lifelong journey and study abroad program provides a good chance for university students in China to begin this journey. In order to maximize students intercultural learning when they are taking this program, intercultural interventions before, during and after the study abroad program are very crucial. These interventions in these three phrases should be well designed and integrated into one whole training system.

\section{References}

Allen, H. W., Dristas, V., \& Mills, N. (2007). Cultural learning outcomes andsummer study abroad. In M. Mantero (Ed.), Identity and second language learning: Culture, inquiry and dialogic activity in educational contexts (pp. 189-215). Charlotte, N.C., USA: Information Age Publishing.

Clarke III, I., Flaherty, T. B., Wright, N. D., \& McMillen, R. M. (2009). Student intercultural proficiency from study abroad programs. Journal of Marketing Education, 31(2), 173-181.

Engle, L., \& Engle, J. (2003). Study abroad levels: Toward a classification of programtypes. Frontiers: The interdisciplinary journal of study abroad, 9(1), 1-20.

Hammer, M. R. (2007). The Intercultural Development Inventory (IDI) Manual (Vol. 3). Ocean Pines, MD: IDI.

Hammer, M. R. (2011). Additional cross-cultural validity testing of the Intercultural Development Inventory. International Journal of International Relations, 35(4), 474-487.

Harvey, T. A. (2013). Facilitating intercultural development during study abroad: A case study of CIEE’s seminar on living and learning abroad (Unpublished Dissertation, Minneapolis, MN: University of Minnesota).

Jackson, J. (2009). Intercultural learning on short-term sojourns. International Journal of Intercultural Education, (Special Issue), 59-71.

Leong, C.-H. (2007). Predictive validity of the multicultural personality questionnaire: A longitudinal study on the socio-psychological adaptation of Asian undergraduates who took part in a study-abroad program. International Journal of Intercultural Relations, 31(5), 545-559.

Lou, K., \& Bosley, G. (2008). Dynamics of cultural contexts: Meta-level intervention in the study abroad experience. In V. Savicki (Ed.). Developing intercultural competence and transformation: Theory, research and application in international education (pp. 276-296). Sterling, VA: Atylus.

Paige, R. M., \& Goode, M. L. (2009). Cultural mentoring: International education professionals and the development of intercultrual competence. In D. K. Deardorff (Ed.), The SAGE handbook of intercultural competence (pp. 333-349). Thousand Oaks, CA: SAGE Publishing.

Paige, R. M., et.al. (2009). Maximizing study abroad: A student's guide to strategies for language and culture learning and use. Minneapolis, MN: Center for Advanced Research in Language Acquisition, University of Minnesota.

Pedersen, P. J. (2010). Assessing intercultural effectiveness outcomes in ayear-long study abroad program. International Journal of Intercultural Relations, 34(1), 70-80.

Tuleja, E. A. (2008). Aspects of intercultural awareness through an MBA study abroad program: Going "Backstage”. Business Communication Quarterly, 71(3), 314-337. 


\section{A CASE STUDY OF INTERCULTURAL INTERVENTIONS FOR CHINESE UNIVERSITY STUDENTS}

Vande Berg, M, Connor-Linton, J., \& Paige, R. M. (2009a). The Georgetown Consortium study: Intervening in student learning abroad. In Frontiers: The Interdisciplinary Journal of Study Abroad, XVIII(18), 1-75.

Vande, B. M., Paige, R. M., \& Lou, K. M. (2012). Student learning abroad: What our students are learning, what they're not, and what we can do about it (pp. 29-30). Sterling, Virginia: Stylus Publishing, LLC.. 